\title{
MARTINS, Albano. Pequeno dicionário privativo seguido de Um punhado de areia. Porto: Edições Afrontamento, 2017.
}

Jorge Vicente Valentim

Universidade Federal de São Carlos (UFSCAR), São Carlos, São Paulo / Brasil jvvalentim@gmail.com

http://orcid.org/0000-0002-9275-9801

Último livro publicado em vida do autor, Pequeno dicionário privativo constitui uma das obras mais singulares do poeta, ensaísta, tradutor e antologista Albano Martins (1930-2018). Como o próprio título sugere, trata-se de uma recolha de extensão curta de expressões caras ao escritor portuense (porque escolheu o Norte de Portugal, mais especificamente as cidades do Porto e de Vila Nova de Gaia, onde fixou sua residência e seus lugares de morança), compondo um conjunto de 46 verbetes, todos eles inseridos numa primeira parte com título homônimo à obra.

$\mathrm{Na}$ melhor tradição dos pequenos poemas em prosa, esse dicionário de Albano Martins figura como mais uma das suas investidas no gênero. Depois de $A$ voz do chorinho ou Os apelos da memória (1987), Rodomel. Rododendro (1989) e O espaço partilhado (1998), no meu entender, a obra revela um poeta no auge da sua produção artísticopoética, com pleno domínio da forma e com uma sensibilidade seletiva, capaz de escolher, sem colocar em risco e sem prejudicar o seu próprio pensamento criador, os termos-chave considerados principais no seu projeto de escrita.

Talvez, por isso, esse dicionário ofertado pelo poeta, para além do aspecto particular e pessoal, indicado no termo adjetivador (privativo), pode ser lido como uma coletânea de termos afetivos, na medida em que cada um deles expressa uma ligação íntima e sentimental do autor com o tema ou o viés reflexivo sugerido pela palavra-chave, sem, no entanto, cair em lugares-comuns ou tentativas de definições superficiais e pouco 
claras. Essa junção da particularidade com a afetividade das e nas palavras pode ser percebida não apenas na primeira parte da obra, mas, também, na sequência de mais 8 poemas em prosa, já não mais pequenos na sua extensão, reunidos na seção final intitulada "Um punhado de areia".

Assim, de A a Z, o leitor tem a oportunidade de, numa única obra, conhecer a reunião das idéias que mais interessam ao poeta e sua materialização em corpos poéticos muito voláteis e, em certa medida, encadeados entre si, posto que exacerbam a expressão subjetiva de um sujeito poético que ora expressa um poder concentracionário na recolha exata de cada expressão, ora alarga as possibilidades semânticas dos encadeamentos possíveis de significados e sentidos que cada termo lhe provoca. Um dos exemplos mais paradigmáticos dessa corrente semântica pode ser encontrado no binômio "Absurdo" e "Acaso":

\section{ABSURDO}

Irmão gémeo do acaso e tão poderoso e presente, como ele, no universo do nosso quotidiano (MARTINS, 2017, p. 9)

ACASO

Tudo é obra sua. Ele é, por isso, o único deus omnipotente. E omnipresente (MARTINS, 2017, p. 11).

Interligados, os dois pequenos poemas expressam a visão agnóstica do autor, sobretudo, no tocante às forças sobre os destinos humanos, marcados pelas vicissitudes e contrariedades típicas do cotidiano. Numa provável aliança com a crença nietzschiana da morte de Deus, o homem surge, aqui, como força centrífuga e centrípeta, impactado pelas energias do único deus possível capaz de interferir na sua trajetória: o acaso.

Essa compreensão dilatada dos encadeamentos de significados na vida humana e das ações e potências, que sobre ela atuam, acaba por repercutir também no poema "Tempo", onde a inexorabilidade da força de cronos sobre todos os seres mostra-se como a única forma de entender a mobilidade, a transitoriedade e a fugacidade das coisas: "Árvores que somos, passam por nós, em corrida, as estações. Sem ruído, caem no chão as folhas e apodrecem. Quem as recolhe é um cão ladrando aos astros - que ninguém ouve" (MARTINS, 2017, p. 52).

Leitor também de Fernando Pessoa, pode se perceber, aqui, uma revisitação muito particular (e, logicamente, privativa) daquela máxima de Ricardo Reis de que a vida "Passa e não fica, nada deixa e nunca regressa" (PESSOA, 2001, p. 256). Mas, ao contrário da placidez e 
da ausência dos "desassossegos grandes" (PESSOA, 2001, p. 256), há uma consciência da angústia diante da degenerescência do corpo - as folhas que, gradativamente, caem no chão e vão apodrecendo - e do esquecimento a que o ser humano está fadado - na contumaz ausência de resposta diante do latido de um cão que as recolhe.

No meu entender, detecta-se a inquietação de um autor que sabe que está a correr contra o tempo e necessita registrar todas as suas afinidades, preocupações e perspectivas, ainda que tenha consciência de que o poder de cronos é impiedoso e a linguagem, muitas vezes, não lhe fornece instrumentos suficientes para dar conta de todas as suas necessidades a serem expressas.

Assim, uma das chaves para entrar e acompanhar esses verbetes de Albano Martins encontra-se, exatamente, no poema "Paixão", onde o autor revela o seu modus vivendi e o seu modus opererandi ao confrontar-se com a palavra e o ofício poéticos: "O seu sinónimo perfeito é sofrimento, mas o sofrimento por amor é o único humanamente tolerável e, mais do que isso, apetecível. Diria mais: a paixão é a única forma digna de enfrentar a vida e resistir aos diários assaltos da morte" (MARTINS, 2017, p. 39).

Ora, não à toa, nesse Pequeno dicionário privativo, Albano Martins concede ao seu leitor a possiblidade de devassar as paixões e as motivações do seu projeto criador. Se, como propõe Bernadette Capelo-Pereira, arte e natura fundem-se nas obras poéticas do autor, explicitando um "afirmado amor pela natureza e uma simbiose com o mundo vegetal, como processo ontológico fundado no movimento e na metamorfose" (CAPELO-PEREIRA, 2015, p. 22), alguns dos poemas em prosa do texto em foco confirmam essa tendência estética: "Acácia", "Água", "Árvores", “Cegonhas", "Cerejas", "Cigarras", "Folha”, "Grilo", "Laranjas", "Lua", "Magnólia", "Papoilas" (1 e 2), "Pássaros", "Rolas", "Romãs", "Rosa" e "Verão" são alguns dos exemplos mais significativos desse olhar apaixonado para o mundo e para os elementos naturais, sem perder a percepção de que todas essas coisas, assim como ele próprio - o poeta -, são transitórias e passageiras.

Vale, no entanto, reiterar que esses pequenos poemas em prosa não se constituem cópias exatas das paisagens e dos objetos a que se remetem, antes devem ser compreendidos como aquelas "formas pregnantes" (COELHO, 1988, p. 154), de que nos fala Eduardo Prado Coelho, através das quais o poeta engendra suscitar a "emergência de uma forma a partir 
de outra forma" (COELHO, 1988, p. 153), ou seja, a capacidade gestaltica de registrar algumas referências empíricas completamente transformadas e remoldadas pela palavra poética.

Já aqui o leitor percebe que a angústia consciente da passagem do tempo e dos seus efeitos colaterais sobre o mundo e sobre o poeta não o leva a destilar uma visão niilista e vitimadora, muito pelo contrário. Enquanto criador, ele insiste salutarmente na capacidade da palavra poética não só de remoldar essa realidade a partir de uma sensibilidade ótica e de um incontido desejo de sorver a vida, mas também de investir numa interligação de sentidos possíveis entre todos esses objetos, sobretudo, quando, explicitamente, expressa esse alargamento semântico. Amor e morte, por exemplo, são palavras irmãs pelo viés linguístico, mas também, e sobretudo, pela sensibilidade poética. Tal ligação e irmandade só podem ser concebidas porque a própria natureza da poesia incide sobre o desenvolvimento de uma capilaridade intertextual, de que o autor é íntimo conhecedor e articulador, seja como leitor, seja como tradutor:

\begin{abstract}
AMOR E MORTE
A segunda sílaba da palavra amor repete a primeira da palavra morte. Talvez por isso, diz-se, o amor e a morte caminham a par. Disse-o Leopardi num poema intitulado «Amor e Morte», nestes termos (traduzo): «Irmãos, a um tempo, amor e morte / foram gerados pela sorte». Mas há também a outra morte, essa a que Bataille chama «pequena», a qual, diz ele, pouco tem a ver «com o horror frio da morte». É do desejo - é do amor - que se trata, afinal. Isso que faz de nós seres humanos e não simples roedores ou animais de estimação (MARTINS, 2017, p. 14).
\end{abstract}

Possuído por uma lógica pragmática em entender a vida e o homem, a conclusão do texto ("Isso que faz de nós seres humanos e não simples roedores ou animais de estimação"), após mostrar as cargas semânticas possíveis da morte e de suas expansões significativas, aponta para uma emergência do presente, enquanto único tempo disponível e possível para a vida. Por isso, esses poemas não estão distantes daquela concepção horaciana de um carpe diem poético, em que cada texto transfigura uma sensação, uma afinidade, um desejo e uma paixão do autor. E tanto assim é que algumas linhas de força da sua poesia comparecem de forma explícita e pontual. Do "mapa-mulher" (LOURENÇO, 2016, p. 536), tão argutamente observado por Eduardo 
Lourenço, à aliança indissolúvel entre "duas experiências: a da construção textual e a da sensualidade" (PEREIRA, 2001, p. 145), sublinhada por Luci Ruas Pereira, por exemplo, os poemas "Beleza", "Fogo", "Mulher", "Paixão", "Perfume" e "Seios" dão-nos uma prova cabal dessa demanda do poeta. Do mesmo modo, "o encontro ideal entre o sujeito do enunciado e o silêncio" (GOMES, 2005, p. 58), enquanto instrumento de reflexão sobre o poder da linguagem e de manipulação desta pelo gesto criador, conforme desenhado por Álvaro Cardoso Gomes, e a sensibilidade concretizada no gesto poético, "onde o olhar e a memória sensitiva convergem na construção de um mundo complexo e multifacetado, onde se imbricam o humano, o espacial e o temporal" (BRANCO, 2004, p. 68-69), defendida por José Fernando Castro Branco, comparecem nos poemas da segunda parte da obra, indicada no próprio título como $\mathrm{Um}$ punhado de areia.

Toda essa segunda seção, não por acaso, é composta por longos poemas em prosa, onde a memória afetiva dos locais de afinidade e afetividade do autor se sobressai como marca efetiva dos mecanismos articulados pela criação poética. Assim, em "Em jeito de poema ou de como a Avenida dos Aliados é agora uma pista", reivindica-se uma paisagem do Porto, outrora revestida de flores que, no seu conjunto, "acariciadas por delicadas mãos, eram o símbolo perene da graça e da beleza" (MARTINS, 2017, p. 65). Enrijecida pela mudança dos ares modernosos, o poeta opõe-se com veemência e com um delicioso e elegante sarcasmo: "Os arquitectos, que da arquitetura conhecem a linha e o traço, mas não a cor, transformaram a avenida numa pita de aterragem para naves espaciais e inscreveram nela o vazio e a aridez planetários" (MARTINS, 2017, p. 65).

Numa nítida referência às alterações urbanas causadas pelas obras do Metro do Porto, em 2005, o poeta rejeita sem pudores o monocromatismo imposto pelo acinzentado dos granitos e reclama a pluralidade das cores e a presença da natureza num espaço de importância coletiva e, sobretudo, de marcante vivência pessoal. No fundo, a rejeição ao novo desenho arquitetônico não soa como uma negação à modernidade, mas incide numa defesa à memória cultural da cidade e dos seus desenhos originais e numa revolta contra a deformação dos meandros afetivos que ligam moradores ao seus espaços de origem e de pertença.

Assim, nesse segundo bloco, nota-se, por um lado, uma movência do poeta tanto por macro-espaços (como a cidade do Porto com suas 
ruas e avenidas), quanto por micro-espaços (a casa paterna e os animais ligados a paisagens pretéritas, como em "Réquiem para dois pequenos melros implumes", "Das pombas" e "Elegia para uma gata angorá"), e, por outro, uma necessidade de fixar nos poemas em prosa a simplicidade de imagens cotidianas que remetem ao seu passado particular, à infância.

Se na primeira parte, o poder de uma poética concentracionária vai moldando cada um dos verbetes-poemas, na segunda, essa mesma potência alarga os tentáculos da memória e concentra, num mesmo texto, todo um conjunto de referências naturais e privativas. Nesse sentido, um dos momentos mais tocantes e sensíveis desse Pequeno dicionário privativo encontra-se em "Infância":

Joguei com ela o pião e ao berlinde, no terreiro da casa. Com ela andei aos grilos, fui aos ninhos, subi às medas de trigo e de centeiro, no ardor de verão. Com ela fui à escola pela mão ou às cavalitas na égua parida do meu pai.

[...]

Infância. A idade das rolas, dos estorninhos e dos melros. Aquelas, empoleiradas às vezes nos eucaliptos e fazendo ninho nos castanheiros perfilados a norte; estes, passando ao largo, em voo rasante, na direção das sarças onde se acoitavam.

Infância. Infância azul e verde, com seus vernizes dourados, sua esdruxula florescência.

Infância. A palavra antes da palavra, antes da fala: in-fância (MARTINS, 2017, p. 68-69).

Ora, se as imagens nesse poema compõem um repertório confluente em virtude do exercício da memória, é na idade intocada e imaculada da infância que o poeta (re)encontra o melhor exemplo do principal instrumento motivador de sua criação poética. É lá, no tempo e no espaço da infância (a mesma que o poeta saúda em "Fonte": "Estão ali os meus oito anos - a minha infância toda"; MARTINS, 2017, p. 25), do in-fans, daquele ser que ainda não é capaz de articular a fala, mas que sente e apreende todo um mundo dinâmico e movente ao seu redor, que Albano Martins redescobre a sua música do silêncio, do instrumento capaz de motivar um gesto, um ato catalizador para, a partir de um pretenso caos, moldar um cosmos particular e privativo.

Assim, as rolas, os melros, os eucaliptos, a casa paterna e os carinhos maternos, mais do que objetos recuperados pela memória, são imagens pregnantes de recordações. Tal como as expressões latinas 
indicam (res + cordis), são coisas do coração que só a expressão sincera e singela, movida pela mais pura afetividade, poderia alcançar e expressar.

Gosto de pensar, portanto, que esse Pequeno dicionário privativo seguido de Um punhado de areia, de Albano Martins, revela o poder uma madura poética concentracionária, as emergências do presente e a necessidade de fixar, pela palavra poética, as importâncias, as inquietações, as afinidades, as afetividades e as paixões do seu autor, enquanto expressão de uma vida dedicada exclusivamente ao ofício poético e à demanda da poesia.

Concluo, portanto, com uma nota, agora, muito particular e privativa minha. Numa época delicada de minha trajetória acadêmica, longe do Brasil, Albano Martins foi aquele que me acolheu (bem como sua família) sem perguntas e sem julgamentos, como se filho dele fosse. Infelizmente, ele não pode ler essa recensão em vida, o que, de certo modo, me dói por não ter conseguido cumprir uma promessa feita a ele. Ainda assim, acredito que lá no reino das Tágides, onde ele certamente repousa e tem um lugar privilegiadíssimo, ele deve estar esboçando aquele sorriso discreto, mas tão expressivo. Do lado de cá, fica esse meu gesto como uma prova de gratidão comovida ao grande poeta e ao ser humano iluminado que foi. À Kay e à Isabel, o meu carinho e a minha admiração por não deixarem o ostracismo apagar as pegadas desse grande escritor de língua portuguesa. Bem haja.

\section{Referências}

BRANCO, J. F. C. Poética do sensível em Albano Martins. Porto: Roma, 2004.

CAPELO- PEREIRA, B. Arte e natureza na obra de Albano Martins. Lisboa: Chiado Editores, 2015.

COELHO, E. P. A noite do mundo. Lisboa: Imprensa Nacional - Casa da Moeda, 1988.

GOMES, Á. C. A melodia do silêncio. Subsídios para o estudo da poesia de Albano Martins. Vila Nova de Famalicão: Quasi Edições, 2001.

LOURENÇO, E. Obras completas III. Lisboa: Fundação Calouste Gulbenkian, 2016. 
MARTINS, A. Pequeno dicionário privativo seguido de Um punhado de areia. Porto: Edições Afrontamento, 2017.

PEREIRA, L. R. O "mapa-mulher" na poesia de Albano Martins. In: LEÃO, I. V. P. de (org.). Uma flauta de areia. Actas do Colóquio/ Homenagem 50 anos de vida literária do poeta Albano Martins. Porto: Edições Universidade Fernando Pessoa, 2001, p. 145-150.

PESSOA, F. Obra poética. Organização, introdução e notas de Maria Aliete Galhoz. Rio de Janeiro: Nova Aguilar, 2001.

Data de recebimento: 7/10/2020 